\title{
Isostructural Cocrystals of 1,3,5-trinitrobenzene Assembled by Halogen Bonding
}

\author{
Jonathan C. Bennion ${ }^{\dagger}$, Leslie Vogt ${ }^{\dagger}$, Mark E. Tuckerman ${ }^{\not \# \S}$ and Adam J. Matzger ${ }^{* \dagger}$ \\ ${ }^{\dagger}$ Department of Chemistry and the Macromolecular Science and Engineering Program, \\ University of Michigan, 930 North University Avenue, Ann Arbor, Michigan 48109-1055, \\ United States \\ ${ }^{\star}$ Department of Chemistry, New York University (NYU), New York, New York 10003, United \\ States \\ ${ }^{\#}$ Courant Institute of Mathematical Sciences, New York University (NYU), New York, New \\ York 10003, United States \\ ${ }^{\S}$ NYU-ECNU Center for Computational Chemistry at NYU Shanghai, 3663 Zhongshan Rd. \\ North, Shanghai 200062, China
}

\section{Table of Contents}

SI 1. Experimental

SI 2. Raman Spectroscopy of TNB Cocrystals

SI 3. Powder X-ray Diffraction of TNB Cocrystals

SI 4. ORTEP Diagrams of TNB Cocrystals

SI 5. Differential Scanning Calorimetry of TNB Cocrystals

SI 6. Computational Optimizations of Unit Cells for TNB Cocrystals/Proposed Cocrystal and Components

SI 7. References 


\section{SI 1. Experimental}

Caution: Although no unplanned detonations were encountered during this work, TNB, TITNB, TBTNB, and TCTNB are all dangerous high explosives. Proper safety practices and equipment were used to prevent an explosion due to friction, heat, static shock, or impact. Be aware that the potential for severe injury exists if these materials are handled improperly.

1,3,5-Trinitrobenzene (TNB) was received from Pfaltz \& Bauer (wetted with $40 \%$ water) and allowed to dry before use. 1,3,5-Triiodo-2,4,6-trinitrobenzene (TITNB), 1,3,5-tribromo-2,4,6trinitrobenzene (TBTNB) and 1,3,5-tricloro-2,4,6-trinitrobenzene (TCTNB) were synthesized as described in the literature. ${ }^{1}$

\section{Crystallization}

Both cocrystals of TNB (1 and $\mathbf{2}$ ) were initially obtained from acetonitrile solutions, with the stoichiometric ratio of the pure components $2: 1$, by slow evaporation and then conditions for growth in pure form was determined. The cocrystal synthesis could be scaled up conveniently with the use of solvent mediated transformation in a slurry of the pure components at room temperature, see below.

\section{2:1 TNB/TITNB (1)}

A $4 \mathrm{~mL}$ glass vial was loaded with $21.31 \mathrm{mg}$ of TNB $(0.1000 \mathrm{mmol}), 29.54 \mathrm{mg}$ TITNB $(0.05000$ $\mathrm{mmol}$ ) and $200 \mu \mathrm{L}$ of dry isopropanol. The vial was sealed and shaken gently for 6 days, during which time the pure components of TNB and TITNB had disappeared and small clear prisms had appeared. This solid was determined to be the $2: 1$ TNB/TITNB cocrystal by both Raman spectroscopy and powder X-ray diffraction.

\section{2:1 TNB/TBTNB (2)}

A $4 \mathrm{~mL}$ glass vial was loaded with $21.31 \mathrm{mg}$ of TNB $(0.1000 \mathrm{mmol}), 22.48 \mathrm{mg}$ TBTNB $(0.05000 \mathrm{mmol}), 150.0 \mu \mathrm{L}$ of dry isopropanol and a small magnetic stir bar. The vial was sealed and stirred gently for 4 days, during which time the pure components of TNB and TBTNB had disappeared and a white powder had appeared. This solid was determined to be the 2:1 TNB/TBTNB cocrystal by both Raman spectroscopy and powder X-ray diffraction. 


\section{Raman Spectroscopy}

Raman spectra were collected using a Renishaw inVia Raman Microscope equipped with a Leica microscope, $633 \mathrm{~nm}$ laser, 1800 lines/mm grating, $50 \mu \mathrm{m}$ slit and a RenCam CCD detector. Spectra were collected in extended scan mode with a range of $100-4000 \mathrm{~cm}^{-1}$ and then analyzed using the WiRE 3.4 software package (Renishaw). Calibration was performed using a silicon standard in static mode.

\section{Powder X-ray Diffraction (PXRD)}

Powder X-ray diffraction patterns were collected on a Bruker D8 Advance diffractometer using $\mathrm{Cu}-\mathrm{K} \alpha$ radiation $(\lambda=1.54187 \AA)$ and operating at $40 \mathrm{kV}$ and $40 \mathrm{~mA}$. Samples were prepared by finely grinding and packing into the depression of a glass slide. The powder patterns were collected by scanning $2 \theta$ from $4^{\circ}$ to $70^{\circ}$ with a step size of $0.02^{\circ}$ and a step speed of 0.5 seconds. To minimize preferred orientation effects, the PXRD patterns of the cocrystals were also obtained on a Rigaku R-Axis Spider diffractometer using $\mathrm{Cu}-\mathrm{K} \alpha$ radiation $(\lambda=1.54187 \AA)$ and operating at $40 \mathrm{kV}$ and $44 \mathrm{~mA}$. Samples were ground and mounted on a CryoLoop ${ }^{\mathrm{TM}}$. Images were collected for 10 minutes with rotating the sample about $\varphi$-axis at $10 \%$ sec, oscillating $\omega$ between $80^{\circ}$ and $140^{\circ}$ at $1^{\circ} / \mathrm{sec}$ with $\chi$ fixed at $45^{\circ}$. The images were integrated from 4 to $50^{\circ}$ with a $0.02^{\circ}$ step size using AreaMax 2.0 software (Rigaku). The data were processed using Jade 8 XRD Pattern Processing, Identification \& Quantification analysis software (Materials Data, Inc.). ${ }^{2}$ The powder patterns were all compared to their respective simulated powder patterns from the single crystal X-ray diffraction structures and were found to be in good agreement with the predicted patterns.

\section{Single Crystal Structure Determination}

Single crystal X-ray diffraction data for cocrystals $\mathbf{1}$ and $\mathbf{2}$ were collected using a Rigaku AFC10K Saturn 944+ CCD-based X-ray diffractometer equipped with a low temperature device and Micromax-007HF Cu-target micro-focus rotating anode $(\lambda=1.54187 \AA)$ operated at $1.2 \mathrm{~kW}$ power $(40 \mathrm{kV}, 30 \mathrm{~mA})$. The X-ray intensities were measured at $85(1) \mathrm{K}$ with the detector placed at a distance $42.00 \mathrm{~mm}$ from the crystal. The data were processed with CrystalClear 2.0 $(\text { Rigaku })^{3}$ and corrected for absorption. The structures were solved and refined with the Bruker SHELXTL (version 2008/4) ${ }^{4}$ software package using direct methods. All non-hydrogen atoms 
were refined anisotropically with the hydrogen atoms placed in a combination of refined and idealized positions.

\section{Differential Scanning Calorimetry (DSC)}

Thermograms for each sample were recorded on a TA Instruments Q20 DSC equipped with a RCS90 chiller. All experiments were conducted in Tzero ${ }^{\mathrm{TM}}$ hermetic aluminum DSC pans under a nitrogen purge with a heating rate of $10{ }^{\circ} \mathrm{C} / \mathrm{min}$, while covering the temperature range of $35^{\circ} \mathrm{C}$ to $400{ }^{\circ} \mathrm{C}$. The instrument was calibrated using an indium standard. Thermograms were analyzed using TA Universal Analysis 2000, V 4.5A.

\section{Computational Optimization of Molecules and Unit Cells}

The atomic positions and unit cells of each crystal were optimized starting from either the experimental structure or an isostructural analogue using CP2K v. 2.6.2. ${ }^{5}$ The QUICKSTEP package $^{6}$ was used with the Gaussian and plane wave (GPW) scheme ${ }^{7}$ to run ab initio Density Functional Theory (DFT) calculations. The PBE exchange-correlation functional ${ }^{8}$ was used with the D3(BJ) dispersion correction, ${ }^{9,10}$ including the C9 term and a cutoff of $18 \AA$. The DZVPMOLOPT-GTH (m-DZVP) or DZVP-MOLOPT-SR-GTH basis sets ${ }^{11}$ were used for $\{\mathrm{H}, \mathrm{C}, \mathrm{N}$, $\mathrm{O}, \mathrm{Cl}\}$ and $\{\mathrm{Br}, \mathrm{I}\}$, respectively, paired with appropriate dual-space GTH pseudopotentials ${ }^{12}$ optimized for the PBE functional. ${ }^{13}$ The calculations made use of the orbital transformation $\operatorname{method}^{14}$ for wave function optimization and the BFGS algorithm for geometry optimization.

Explicit supercells were constructed for each system such that each cell vector spans at least two independent molecules, but crystallographic symmetry was not imposed during the optimizations. For all systems, SCF convergence was set to $1 \mathrm{E}-7$ Hartree using the fine integration grid and the following QUICKSTEP variables: 5 grids with a cutoff of 900 Ry and a relative cutoff of $70 \mathrm{Ry}$, EPS_RHO $=1 \mathrm{E}-12$, EPS_PGF_ORB $=1 \mathrm{E}-7$. The optimization parameters were selected based on convergence of the energy per unit cell to $<1 \mathrm{E}-5$ Hartree, although due to computational cost of the large supercells, the dispersion cutoff of $18 \AA$ is converged only to 1E-4 Hartree. The dispersion cutoff was smaller than the length of any supercell vector.

Optimizations of single molecules of TITNB, TBTNB, and TCTNB were performed by placing each molecule in a $20 \AA^{3}$ cell. The electrostatic potential was calculated on a grid using CP2K and visualized at the $\rho=0.002$ a.u. isosurface using VMD v. 1.9.1. The optimized cell 
parameters for the TNB, TXTNB, and cocrystal systems are reported in Tables S1 - S3. After optimizations, deviations from experimental cell vectors and unit cell volumes are $\leq 4.4 \%$ and $\leq$ $4.7 \%$, respectively. The total system energy for each crystal is reported in Table S4. The relative lattice energies of $-11.5,-8.2$, and $-8.5 \mathrm{~kJ} / \mathrm{mol}$ for $2: 1 \mathrm{TNB} / \mathrm{TITNB}$, TNB/TBTNB and TNB/TCTNB, respectively, are determined by subtracting the cocrystal system energy per asymmetric unit from the total lattice energy of the coformers in an equivalent ratio. Conformational changes from the gas phase single molecule geometries are minimal and all coformers are in the same solvent environment; therefore, the thermodynamic cycle reduces to the difference between the cocrystal lattice energy and the lattice energies of $(2 *$ TNB Form I + TXTNB). 


\section{SI 2. Raman Spectroscopy of TNB Cocrystals}

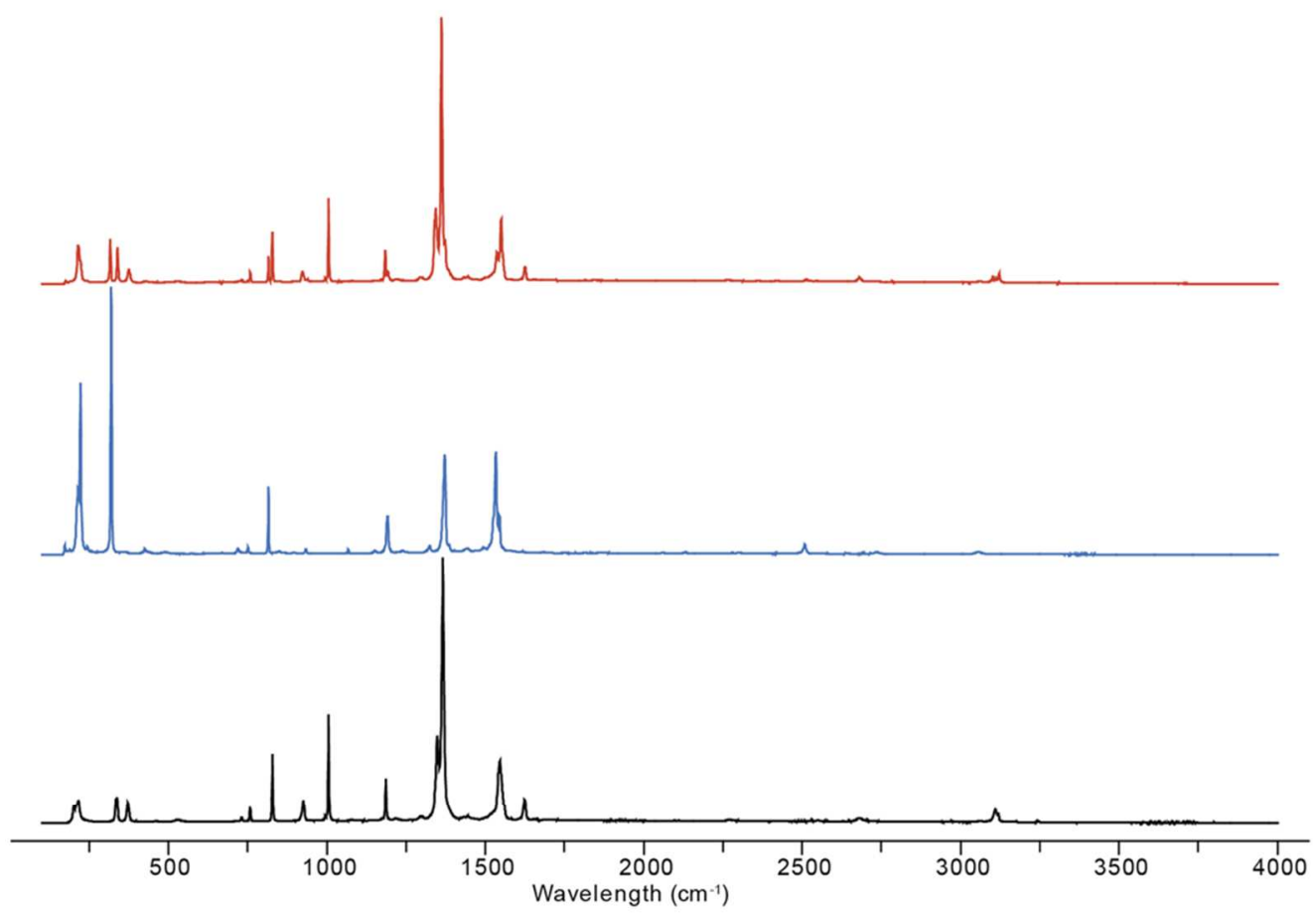

Figure S1. Raman spectra of 1, TITNB, and TNB (from top to bottom).

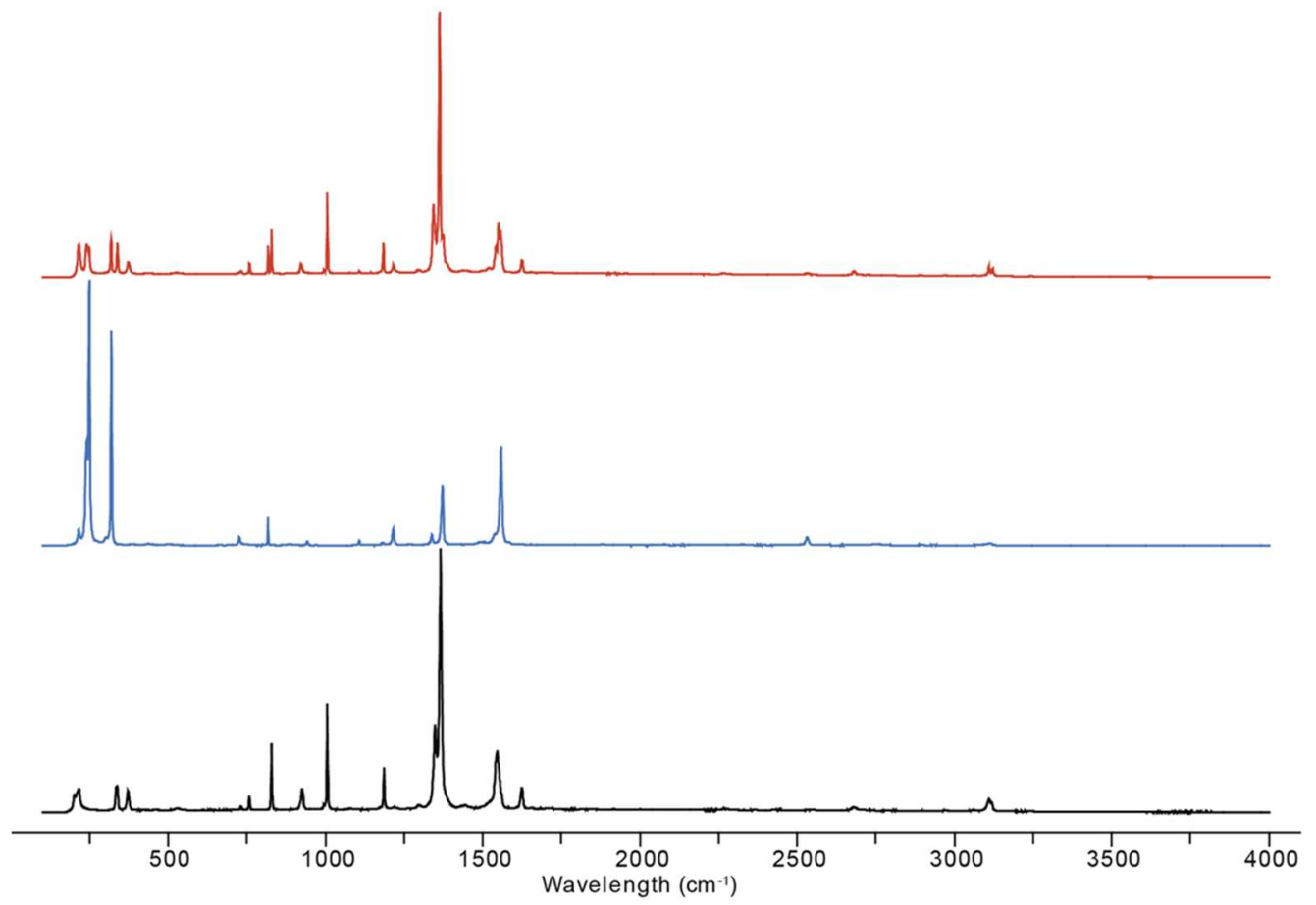

Figure S2. Raman spectra of 2, TBTNB, and TNB (from top to bottom). 


\section{SI 3. Powder X-ray Diffraction Patterns of TNB Cocrystals}

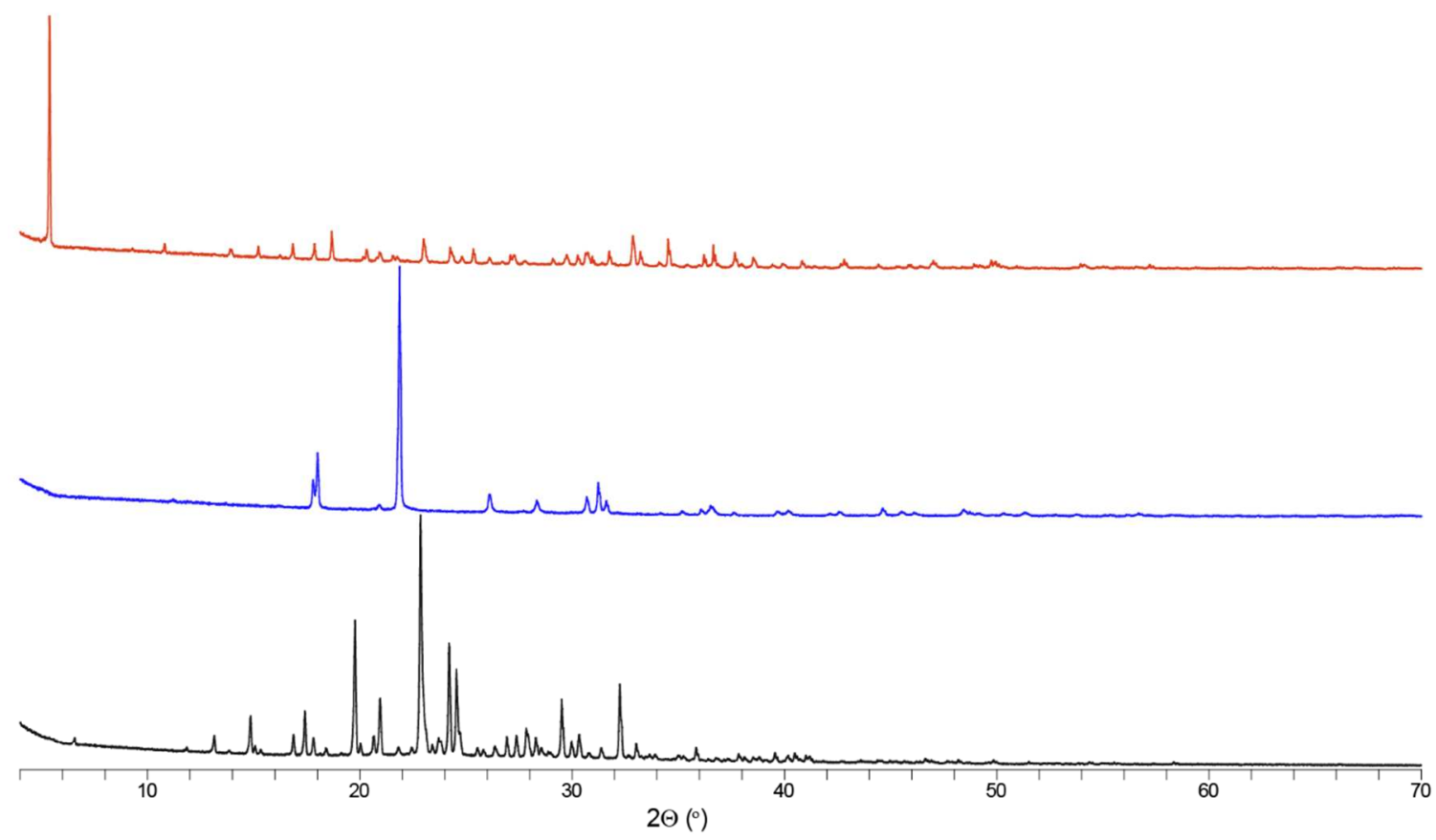

Figure S3. PXRD patterns of 1, TITNB, and TNB (from top to bottom).

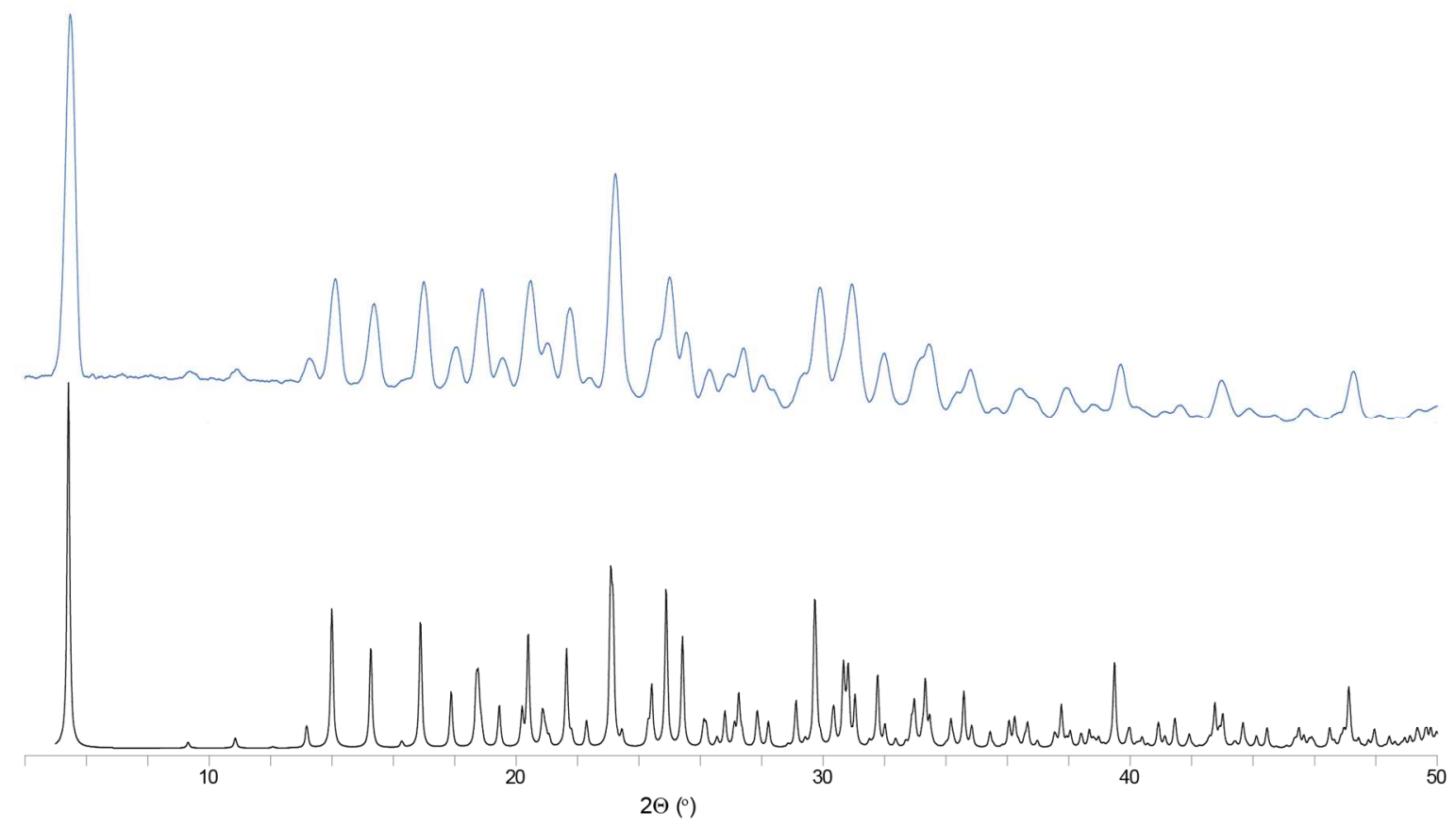

Figure S4. PXRD patterns of 1 and the simulated structure of 1 from the CIF (from top to bottom). 


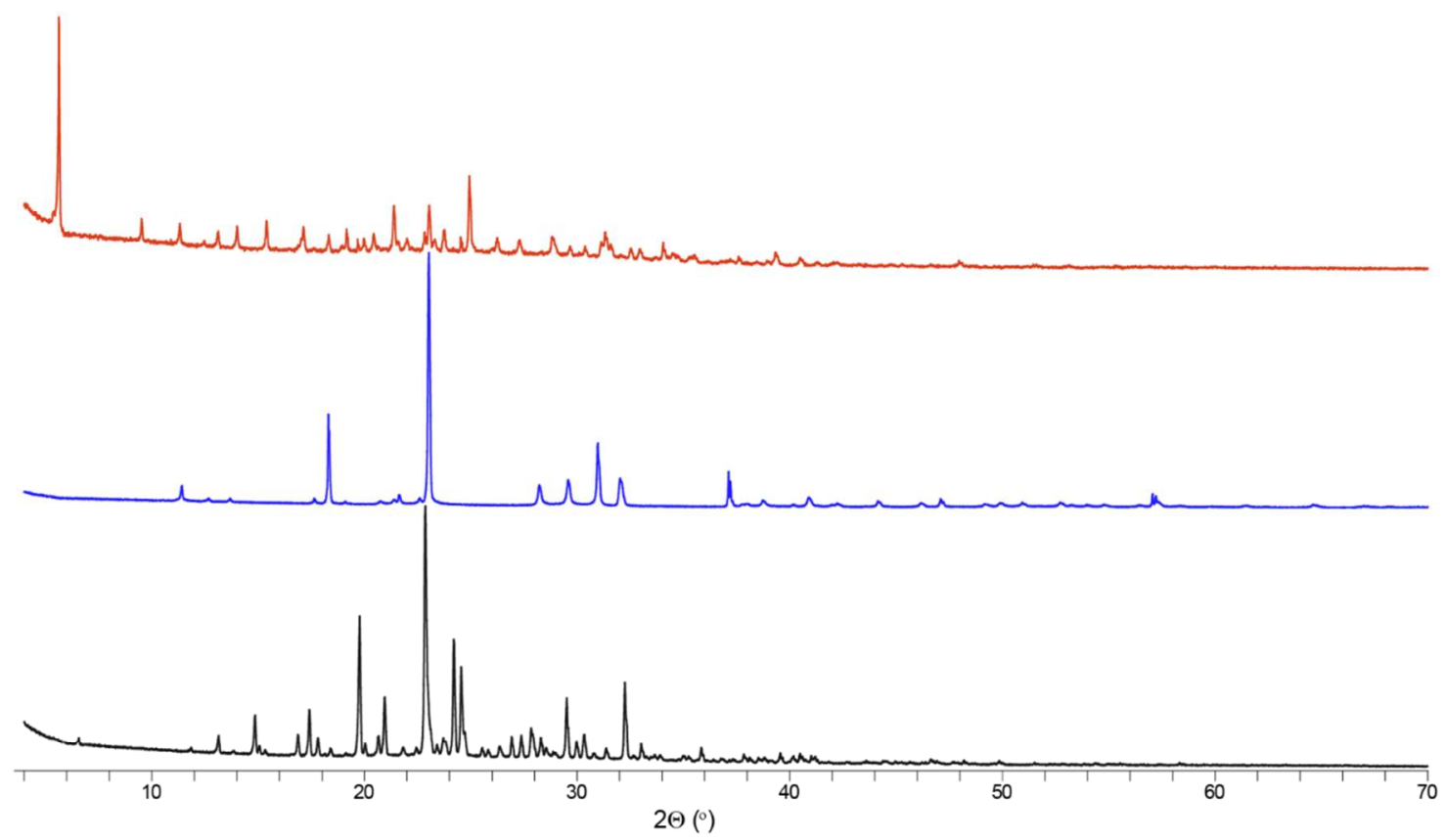

Figure S5. PXRD patterns of 2, TBTNB, and TNB (from top to bottom)

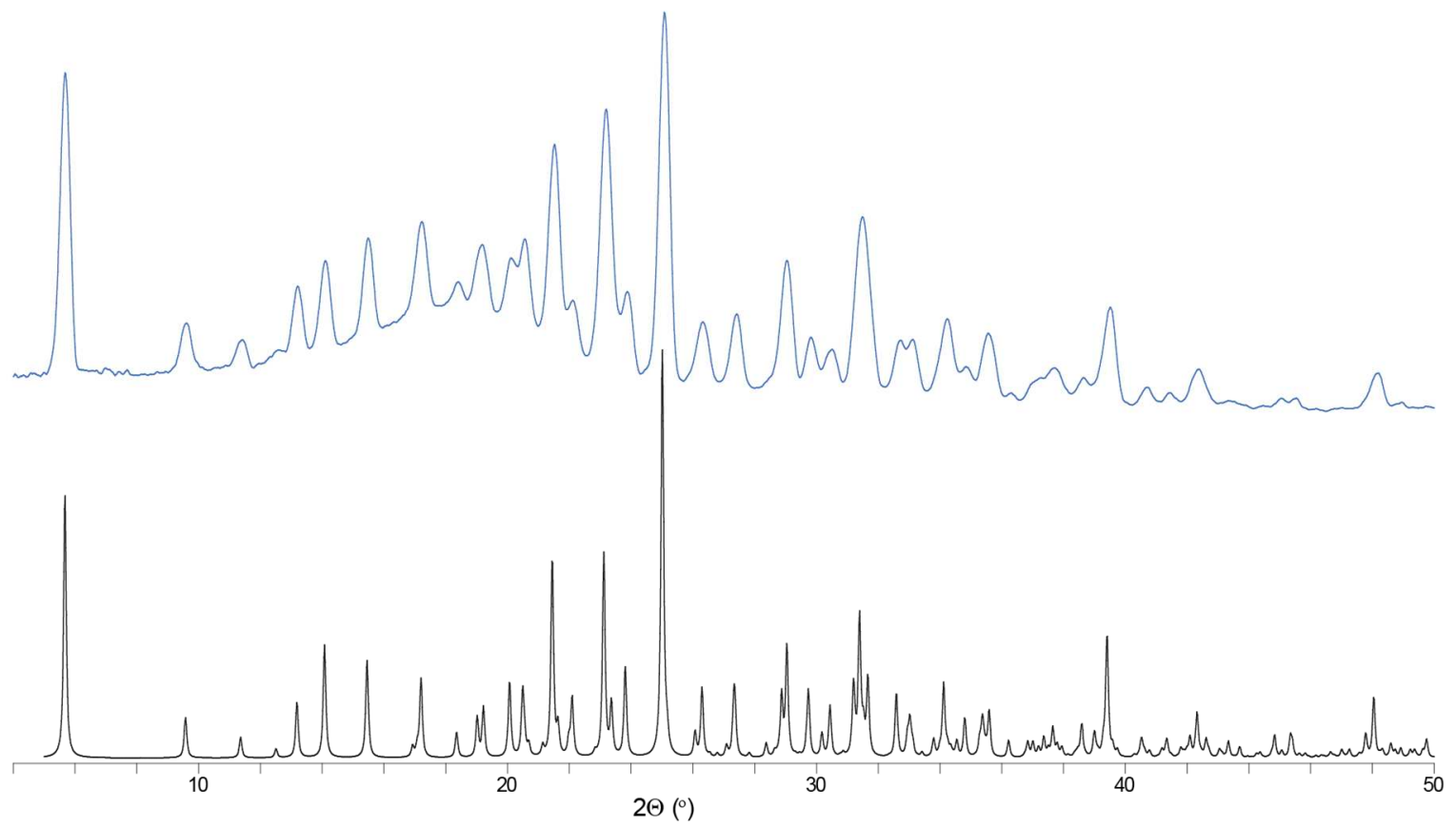

Figure S6. PXRD patterns of $\mathbf{2}$ and the simulated structure of $\mathbf{2}$ from the CIF (from top to bottom). 


\section{SI 4. ORTEP Diagrams of TNB Cocrystals}
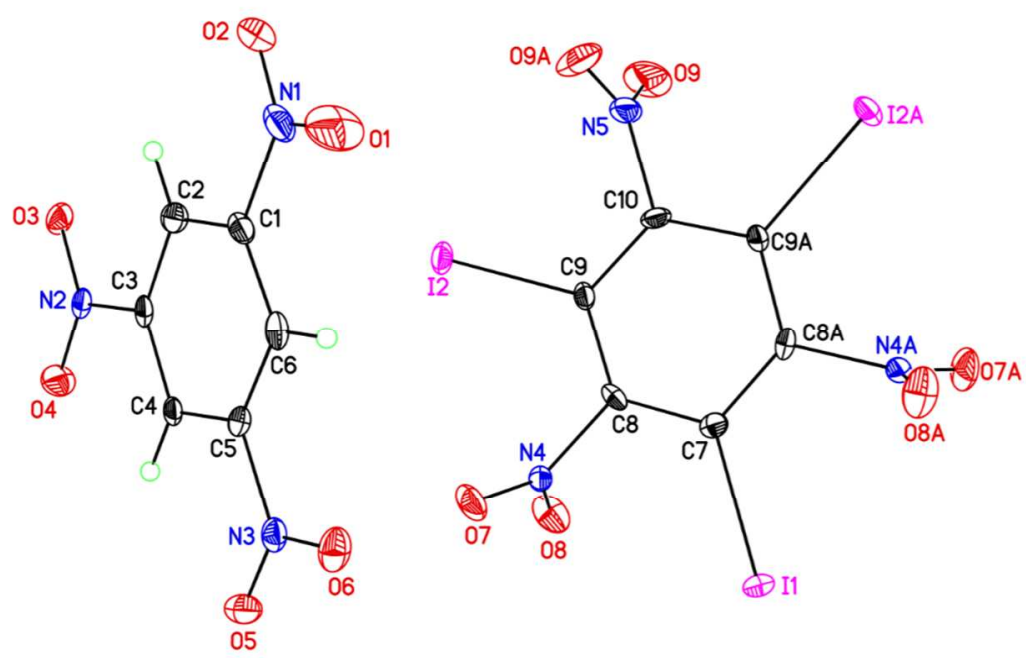

Figure S7. ORTEP diagram for 1 collected at $85 \mathrm{~K}$ with thermal ellipsoids of $50 \%$ probability.
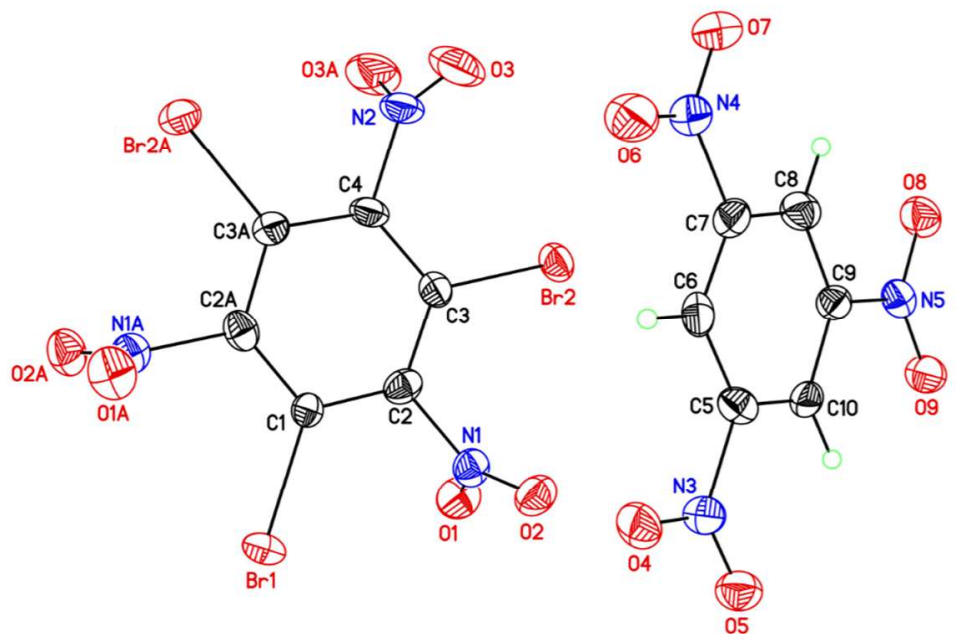

Figure S8. ORTEP diagram for 2 collected at $85 \mathrm{~K}$ with thermal ellipsoids of $50 \%$ probability. 
SI 5. Differential Scanning Calorimetry of TNB Cocrystals

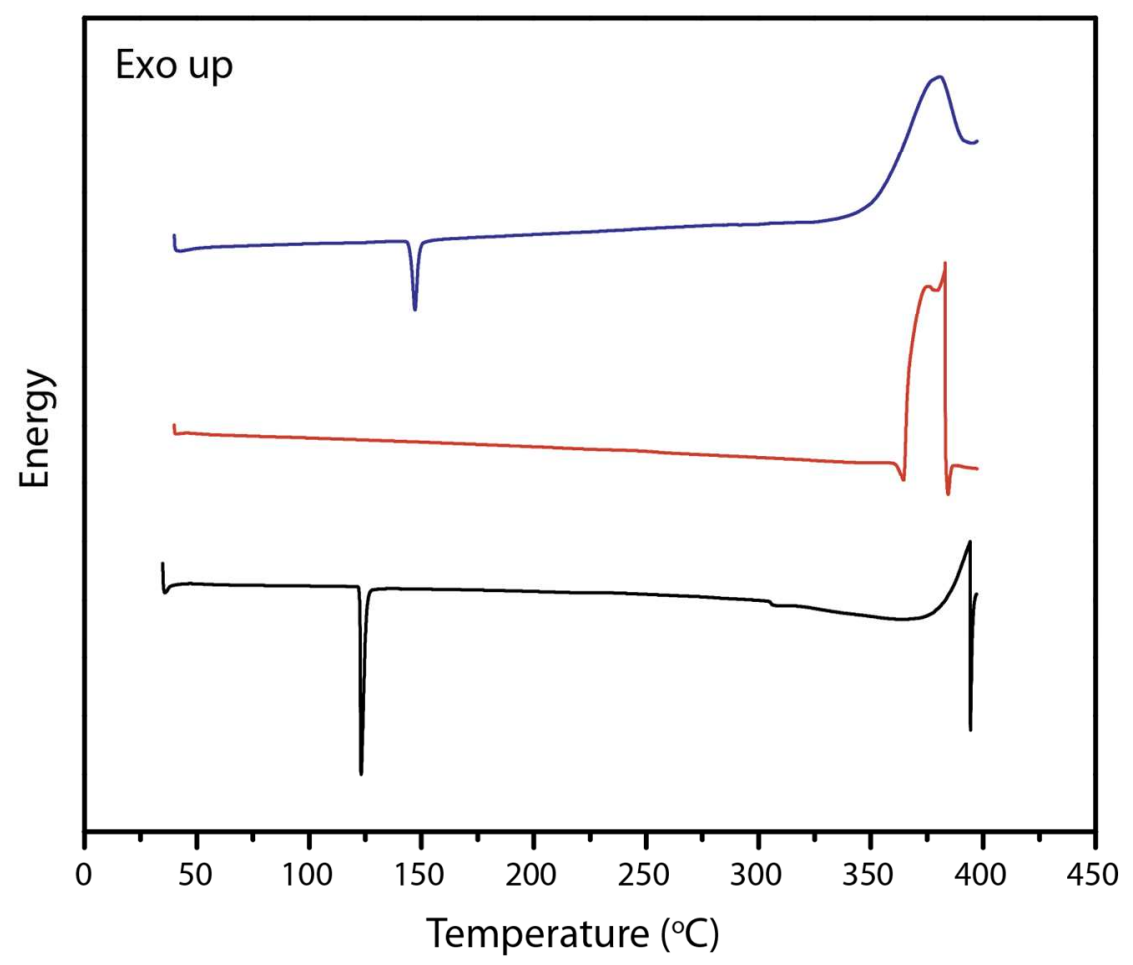

Figure S9. Typical DSC traces of 1, TITNB, and TNB (from top to bottom).

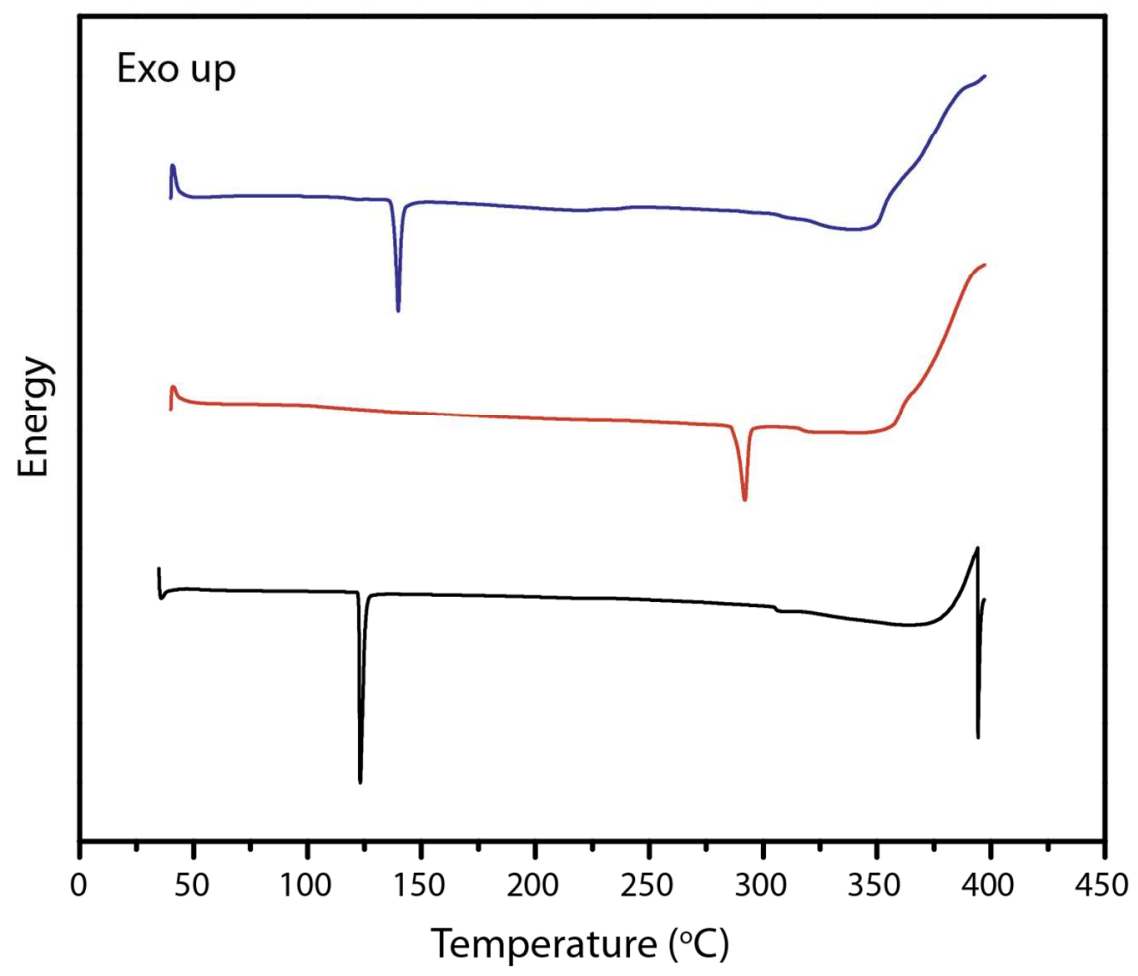

Figure S10. Typical DSC traces of 2, TBTNB, and TNB (from top to bottom). 


\section{SI 6. Computational Optimizations of Unit Cells for TNB Cocrystals/Proposed Cocrystal and Coformers}

Table S1. Optimized Cell Parameters for TNB Polymorphs

\begin{tabular}{|c|c|c|c|c|c|c|c|}
\hline \multicolumn{2}{|c|}{ Cell parameters $\left(\AA ̊,^{\circ}\right)$} & $\mathbf{a}$ & b & c & $\beta$ & $\begin{array}{l}\text { Molecular } \\
\text { Volume }\left(\AA^{3}\right)\end{array}$ & $\begin{array}{l}\text { Relative } \\
\text { Energy } \\
\text { (kJ/mol) }\end{array}$ \\
\hline \multirow[t]{2}{*}{ Form I } & Observed $^{\mathrm{a}}$ & 12.587 & 9.684 & 26.860 & 90.0 & 204.6 & \multirow[b]{2}{*}{+0.6} \\
\hline & $\begin{array}{l}\text { Calculated } \\
\text { b }\end{array}$ & $\begin{array}{l}12.800 \\
(1.7 \%)\end{array}$ & $\begin{array}{l}9.781 \\
(1.0 \%)\end{array}$ & $\begin{array}{l}27.113 \\
(0.9 \%)\end{array}$ & $\begin{array}{l}90.0 \\
(0.0 \%)\end{array}$ & $\begin{array}{l}212.2 \\
(3.7 \%)\end{array}$ & \\
\hline \multirow[t]{2}{*}{ Form III } & Observed $^{\mathrm{a}}$ & 12.896 & 5.723 & 11.287 & 98.19 & 206.1 & \multirow[b]{2}{*}{0.0} \\
\hline & $\underset{b}{\text { Calculated }}$ & $\begin{array}{l}12.992 \\
(0.7 \%)\end{array}$ & $\begin{array}{l}5.911 \\
(3.3 \%)\end{array}$ & $\begin{array}{l}11.178 \\
(-1.0 \%)\end{array}$ & $\begin{array}{l}99.82 \\
(1.7 \%)\end{array}$ & $\begin{array}{l}211.4 \\
(2.6 \%)\end{array}$ & \\
\hline
\end{tabular}

${ }^{a}$ Experimental structures from TNBENZ11 and TNBENZ13 for Form I and III, respectively. ${ }^{15 \mathrm{~b}}$ Relative deviations from experimentally observed values.

Table S2. Optimized Cell Parameters for TXTNB Crystals

\begin{tabular}{|c|c|c|c|c|c|c|c|c|}
\hline \multicolumn{2}{|c|}{ Cell parameters $\left(\AA,^{\circ}\right)$} & $\mathbf{a}$ & b & c & $\boldsymbol{\alpha}$ & $\boldsymbol{\beta}$ & $\gamma$ & $\begin{array}{l}\text { Molecular } \\
\text { Volume }\left(\AA^{3}\right)\end{array}$ \\
\hline \multirow[t]{3}{*}{ TITNB } & Observed $^{\mathrm{a}}$ & 10.906 & 9.951 & 12.857 & 90.00 & 92.75 & 90.00 & 348.4 \\
\hline & Calculated & 11.000 & 9.981 & 12.764 & 90.00 & 92.77 & 90.00 & 349.9 \\
\hline & & $(0.9 \%)$ & $(0.3 \%)$ & $(-0.7 \%)$ & $(0.0 \%)$ & $(0.0 \%)$ & $(0.0 \%)$ & $(0.4 \%)$ \\
\hline \multirow[t]{3}{*}{ TBTNB } & Observed $^{\mathrm{c}}$ & 10.042 & 9.625 & 12.572 & 90.00 & 94.83 & 90.00 & 302.7 \\
\hline & Calculated & 9.941 & 9.719 & 13.122 & 90.00 & 93.16 & 90.00 & 316.4 \\
\hline & $\mathrm{b}$ & $(-1.0 \%)$ & $(1.0 \%)$ & $(4.4 \%)$ & $(0.0 \%)$ & $(-1.8 \%)$ & $(0.0 \%)$ & $(4.5 \%)$ \\
\hline \multirow[t]{3}{*}{ TCTNB } & Observed $^{\mathrm{d}}$ & 12.137 & 12.181 & 11.694 & 100.39 & 100.10 & 78.02 & 274.4 \\
\hline & Calculated & 12.014 & 12.284 & 12.062 & 101.11 & 100.31 & 79.39 & 282.9 \\
\hline & & $(-1.0 \%)$ & $(0.8 \%)$ & $(3.1 \%)$ & $(0.7 \%)$ & $(0.2 \%)$ & $(1.7 \%)$ & $(3.1 \%)$ \\
\hline
\end{tabular}

${ }^{\mathrm{a}}$ Experimental structure from WUGVUR. ${ }^{1 \mathrm{~b}}$ Relative deviations from experimentally observed values. ${ }^{\mathrm{c}}$ Experimental structure from HUFXAJ. ${ }^{1 \mathrm{~d}}$ Experimental structure from WANMON. ${ }^{16}$ 
Table S3. Optimized Cell Parameters for TNB/TXTNB Cocrystals

\begin{tabular}{llrrrr}
\hline Cell parameters $\left(\boldsymbol{\AA}^{\circ},{ }^{\circ}\right)$ & a & \multicolumn{1}{c}{ b } & \multicolumn{1}{c}{ c } & \multicolumn{1}{c}{$\boldsymbol{\beta}$} \\
\hline 2:1 TNB/TITNB & Observed $^{\mathrm{a}}$ & 32.174 & 9.838 & 9.431 & 90.0 \\
& Calculated & 32.540 & 9.918 & 9.611 & 90.0 \\
& & $(0.9 \%)$ & $(0.8 \%)$ & $(1.9 \%)$ & $(0.0 \%)$ \\
\hline $2: 1 \mathrm{TNB} / \mathrm{TBTNB}$ & Observed $^{\mathrm{a}}$ & 30.451 & 9.601 & 9.752 & 90.0 \\
& Calculated & 31.096 & 9.734 & 9.854 & 90.0 \\
& $\mathrm{~b}$ & $(2.1 \%)$ & $(1.4 \%)$ & $(1.0 \%)$ & $(0.0 \%)$ \\
\hline 2:1 TNB/TCTNB & Calculated & 30.488 & 9.608 & 9.994 & 90.0 \\
\hline
\end{tabular}

${ }^{a}$ Experimental structures reported in this work ${ }^{b}$ Relative deviations from experimentally observed values.

Table S4. Calculated System Energy per Asymmetric Molecule Unit

\begin{tabular}{lr}
\hline System & $\mathbf{( k J / m o l )}$ \\
\hline TNB Form I & -424460.24 \\
TNB Form III & -424460.89 \\
\hline TITNB & -509850.88 \\
TBTNB & -525288.18 \\
TCTNB & -537685.14 \\
\hline $2: 1$ TNB/TITNB & a \\
$2: 1$ TNB/TBTNB & -1358782.82 \\
$2: 1$ TNB/TCTNB & -1374216.90 \\
\hline
\end{tabular}

${ }^{\text {a }}$ Energy per asymmetric unit (2 TNB + 1 TXTNB) 


\section{SI 7. References}

(1) Landenberger, K. B.; Bolton, O.; Matzger, A. J. J. Am. Chem. Soc. 2015, 137, 5074.

(2) Jade Plus 8.2 ed.; Materials Data, Inc. 1995-2007.

(3) CrystalClear Expert 2.0 r12, Rigaku Americas and Rigaku Corporation (2011), Rigaku Americas, 9009, TX, USA 77381-5209, Rigaku Tokyo, 196-8666, Japan.

(4) Sheldrick, G.M. SHELXTL, v. 2008/4; Bruker Analytical X-ray, Madison, WI, 2008.

(5) Hutter, J.; Iannuzzi, M.; Schiffmann, F.; VandeVondele, J. WIREs Comput. Mol. Sci. 2014, 4, 15.

(6) VandeVondele, J.; Krack, M.; Mohamed, F.; Parrinello, M.; Chassaing, T.; Hutter, J. Comput. Phys. Commun. 2005, 167, 103.

(7) Lippert, G.; Hutter, J.; Parrinello, M. Mol. Phys. 1997, 92, 477.

(8) Perdew, J. P.; Burke, K.; Ernzerhof, M. Phys. Rev. Lett. 1996, 77, 3865.

(9) Grimme, S.; Antony, J.; Ehrlich, S.; Krieg, H. J. Chem. Phys. 2010, 132, 154104.

(10) Grimme, S.; Ehrlich, S.; Goerigk, L. J. Comput. Chem. 2011, 32, 1456.

(11) VandeVondele, J.; Hutter, J. J. Chem. Phys. 2007, 127, 114105.

(12) Goedecker, S.; Teter, M.; Hutter, J. Phys. Rev. B: Condens. Matter 1996, 54, 1703.

(13) Krack, M. Theor. Chem. Acc. 2005, 114, 145.

(14) VandeVondele, J.; Hutter, J. r. J. Chem. Phys. 2003, 118, 4365.

(15) Thallapally, P. K.; Jetti, R. K. R.; Katz, A. K.; Carrell, H. L.; Singh, K.; Lahiri, K.; Kotha, S.; Boese, R.; Desiraju, G. R. Angew. Chem. Int. Ed. 2004, 43, 1149.

(16) Gerard, F.; Hardy, A.; Becuwe, A. Acta Cryst. C 1993, 49, 1215. 